\title{
El hecho moral en Zubiri: una lectura fenomenológica
}

\author{
URBANO FERRER SANTOS \\ Universidad de Murcia (España) \\ ferrer@um.es
}

\begin{abstract}
Resumen
En el pensamiento de X. Zubiri lo moral es un hecho que está enraizado antropológicamente, y no una mera propiedad de los actos humanos. Lo examino en tres pasos sucesivos. Primero, mostrando las estructuras antropológico-morales que son la justificación y la voz de la conciencia. Segundo, extrayendo las implicaciones antropológicas de conceptos éticos centrales, tales como la felicidad, el bien moral y los deberes, por este orden. Por último, la moralidad social y la moralidad histórica no son aplicaciones especiales de conceptos ya definidos, sino dimensiones antropológicas que vehiculan primariamente el hecho moral, en la medida en que la socialidad pertenece al proceso de personalización y en la medida en que la moralidad se transmite históricamente.
\end{abstract}

Palabras clave: felicidad, bien moral, deber, dimensiones, justificación.

\section{The fact Zubiri moral: a phenomenological reading}

\begin{abstract}
In the thought of X. Zubiri the moral reality is rooted anthropologically, and is not a mere property of human acts. I examine it in three steps. First, by showing the moral-anthropological structures of the justification and the voice of the conscience. Secondly, through the anthropological implications of central ethical concepts, such as hapiness, moral good and duties, according to this order. Finally, social morality and historical morality are not special applications of already defined concepts, but anthropological dimensions which serve as vehicles of the moral fact, insofar as sociality belongs to the process of personalization and morality is historically transmited.
\end{abstract}

Key words: hapiness, moral good, duty, dimensions, justification.

Doctor en Filosofía por la Universidad Complutense de Madrid. Catedrático de Filosofía Moral en la Universidad de Murcia. Profesor visitante de la Universidad de Dresde. Hizo su tesis sobre la intencionalidad en Husserl. Su campo de especialización es la ética fenomenológica y el personalismo. También se ha ocupado de cuestiones de ética aplicada, como la Bioética y la ética social y política. Miembro de la Sociedad Española de Fenomenología (SEFE), Asociación Española de Bioética (AEBI), Asociación de Estudios Personalistas (AEP). Entre sus publicaciones destacan Perspectivas de la acción humana (1990), ¿Qué significa ser persona? (2002), Desarrollos de Ética fenomenológica (2003), Welt und Praxis. Schritte zu einer phänomenologischen Handlungstheorie (2006) o el libro Para comprender a Edith Stein (2009), del que es editor. 
Lo moral es caracterizado por Zubiri ${ }^{1}$ como apropiación de posibilidades $^{2}$. No es algo que se añade extrínsecamente a los actos, sino que es el hombre el que es constitutivamente moral: es el "tener que tener" posibilidades apropiadas, distintas de las meramente físicas. Lo moral son propiedades en sentido reduplicativo, ya que no sólo me son propias al modo de las propiedades físicas, sino que además han sido apropiadas (me pertenecen como propias) para definir mediante ellas mi personalidad. Mientras las propiedades naturales lo son por emergencia de la cosa física, las propiedades por apropiación, como virtud y ciencia, son sólo posibilidades antes de su apropiación efectiva. Unas y otras propiedades no difieren sólo por su contenido, sino por el modo mismo de ser propias (las unas por naturaleza, las otras por apropiación). «La realidad sustantiva cuyo carácter físico es tener necesariamente propiedades por apropiación, es justo lo que yo entiendo por realidad moral» ${ }^{3}$.

Ambos tipos de propiedades aparecen sin la mediación enunciativa de la cópula: las unas, exponiendo el «fisicar» de la fisis (el agua licúa, el fuego arde, el árbol crece, el salto salta, el hombre engorda...); las otras, convirtiéndose en tales por la apropiación de posibilidades. Las dos son, pues, propiedades que no recaen sobre un sujeto desligable de ellas, sino que articulan estructuralmente una realidad sustantiva. Pero ni siquiera en términos enunciativos se dejan separar de un sujeto de atribución, como sería el caso en «Pedro es delgado». Pues en las propiedades físicas el «es» se trueca en el «estar siendo» de la acción verbal (el fuego está ardiendo, el árbol está creciendo...) y en las posibilidades apropiadas se trata de lo que se mantiene como querido (en-érgeia, en el sentido etimológico de lo que queda activamente de un modo inmanente en el querer), frente a lo meramente sido con anterioridad a toda actividad, como es el caso de las tendencias naturales antes de ser como realidad efectivamente querida y aceptada ${ }^{4}$.

Son propiedades, las segundas, que se apropian por razón de su contenido en orden a deponer en ellas como reales la propia realidad;

\footnotetext{
$1 \quad$ Siglas de las obras de Zubiri: SH (Sobre el hombre, 1986); SSV (Sobre el sentimiento y la volición, 1992); SE (Sobre la esencia, 1972); HD (Hombre y Dios, 1984); IRE (Inteligencia sentiente. I: Inteligencia y Realidad, 1981); IRA (Inteligencia sentiente. III: Inteligencia y Razón, 1983); PFHR (El problema filosófico de la Historia de las Religiones, 1993); TDSH (Tres dimensiones del ser humano: individual, social, histórica, 2006). Todas las citas están tomadas de Alianza Editorial. Fundación Xavier Zubiri, excepto Sobre la esencia, $4^{a}$ edición, Sociedad de Estudios y Publicaciones.

2 SH, 374; SSV, 266.

3 SE, 164.

4 SSV, 74.
} 
por tanto, la realidad apropiada está connotada como posibilidad propia, y lo apropiable de esa realidad es su contenido. Son los dos momentos que aparecen coimplicados en primer término en el acto de fruición de la voluntad: en «esto es lo que realmente quiero» resaltan, en efecto, la realidad de lo querido y su talidad o contenido determinado.

En la apropiación está, además, supuesta la autoposesión, que caracteriza a la persona como su modo de ser, ya que es una apropiación no meramente constatada desde fuera, sino realizada por mí. En otros términos: para poder apropiarme unas posibilidades, tengo que tenerme por propio, y esta suidad o autoposesión es lo distintivo de la persona. Así se pone de manifiesto en el carácter, que para Zubiri «es la definición misma de lo que es una propiedad apropiada por razón de su apropiación» ${ }^{5}$. Así pues, las propiedades morales son las que posee el hombre en forma de carácter por apropiación; antes que la diversidad de caracteres humanos está, ciertamente, el ser carácter o tener que forjarse a sí mismo, tenerse en propio mediante los actos. El bien unitario sería la máxima posibilidad del hombre, ya apropiada como felicidad y contraída luego a uno u otro bien.

Esta dimensión moral constitutiva del hombre ha sido puesta de manifiesto de varios modos a lo largo de la Historia de la Ética en forma de experiencia. Señalaré aquí dos ejemplos de esta experiencia: a) la sentencia socrática del Gorgias de que «es menos malo padecer una injusticia que cometerla» da expresión a una de las modalidades de experiencia moral; la experiencia se hace necesaria porque no se parte de una noción a priori suficiente: el saber de lo bueno y lo malo en términos morales no es, en efecto, meramente abstracto, pero la experiencia que, en consecuencia, reclama es cualitativamente moral, no es simplemente una vivencia, sino un ergon, según denominación de Zubiri ${ }^{6}$; b) un segundo ejemplo es la experiencia de la responsabilidad, como forma negativa de lo moral: me siento responsable por lo que no he hecho debiéndolo hacer, por aquello de que no he sido el autor - aun concerniéndome-, aun cuando en un sentido meramente material lo haya podido ejecutar como mero agente, pero en todo caso sin haberlo asumido proyectivamente como autor; el reverso positivo de la responsabilidad tomada en este sentido es la justificación, y es mediante ella como Zubiri accede en primer término a la experiencia moral.

SH, 377.

SH, 376. 


\section{La justificación y la voz de la conciencia como enclaves antropológico-morales}

La justificación es la contrapartida de la falta de ensamblaje en el hombre entre unas estructuras instintivas y el medio circundante. Mientras la conducta animal se mueve dentro de un medio ajustado a su dotación específica, el hombre carece de especificidad biológica y, correlativamente, también está falto de un mundo en torno específico, abriéndose así al mundo como totalidad. Esta ausencia de justeza entre conducta inespecífica y mundo, en tanto que horizonte indefinidamente desplazable, trae consigo que el hombre tenga que justificar (iustum facere), hacer el ajustamiento que no le viene dado. Para ello recurre al orbe de las posibilidades, desde las que dar cuenta de lo decidido realizar. Tal entretejimiento de posibilidad y realidad juega un papel de primer orden en la moralidad, en tanto que realización propia a través de las posibilidades.

Pero la justificación no sólo se presenta por el lado subjetivo, sino que también ha de ser justificada la posibilidad que en particular es elegida como posibilitante de la conducta, vale decir, como aquella a la que se da la preferencia sobre las otras dentro del sistema de las posibilidades objetivas. Justificar la posibilidad elegida es tanto como conmensurarla con la razón de bien que reside en ella. Según Zubiri: «Cuando decimos que el hombre, en virtud de sus tendencias, se abre a un sistema de coordenadas dentro del cual va a inscribir las cosas como preferibles las unas respecto de las otras, lo que es menester decir es que el ámbito que se le abre al hombre es el ámbito de la bondad, de la realidad buena» ${ }^{7}$. La justificación objetiva está, pues, en que lo elegido sea elegible, lo que equivale a decir que encuentre en el bien una razón interna que lo valide o justifique.

A este respecto, la interpretación de Aranguren de la justificación como concerniente a la moral como estructura, distinta y complementaria de la moral como contenido ${ }^{8}$, si bien tiene un cierto apoyo en Zubiri, no se encuentra en este expressis verbis ${ }^{9}$ y no parece del todo coherente con la dimensión objetiva de la justificación, que remite ya a los contenidos buenos en razón de la mediación que corresponde a la posibilidad. Pues el bien moral no lo es al margen de la prevalencia

SH, 308-9.

J. L. L. Aranguren: Ética. Alianza, Madrid, 49.

Así lo señala también J. COROMINAS: Ética primera. Aportación de Xavier Zubiri al debate ético contemporáneo. Desclée de Brower, Bilbao 2000, 142 ss. Bien es verdad que tampoco está en Zubiri la expresión de ética primera, en el sentido en que la utiliza el autor. 
concedida a una u otra de las posibilidades inscritas en el horizonte de proyección y realización humana.

Además de la justificación toma en cuenta Zubiri otro hecho de experiencia de innegable significación moral, como es la voz de la conciencia, pero lo notable es que se topa con ella en el contexto de la inquietud antropológica, que deriva del carácter enigmático que acompaña a la propia realidad (es lo que llama problematismo de la fundamentalidad o el «qué va a ser de mí») y que es también concomitante de la acción (problematismo ahora de la determinación de la propia volición o «qué voy a hacer de mí»). El tratamiento zubiriano de la voz de la conciencia no es subsiguiente, por tanto, a los dictados de los deberes ni a la percepción de los valores (como es el caso de Scheler), sino que se delinea desde el carácter absoluto-relativo de mi realidad sustantiva: por ser esta absoluta, puede haber para ella una voz que la invoque de modo «inapelable e irrefragable», es decir, con absolutez; y por ser relativa la sustantividad humana, es una voz que no reposa sobre mí mismo, sino que se refiere a lo que voy a ser o tengo por delante (aunque pueda enjuiciar también acciones pasadas, pero sólo de un modo derivado).

Otro procedimiento para advertir el arraigo antropológico de la voz de la conciencia es desde la intelección sentiente: como sentiente, tiene el carácter notificante y clamoroso que procede del sentido del oído; como intelección, aquello que es notificado y que clama es la realidad misma en tanto que inteligida. «La vOz de la conciencia es el clamor de la realidad camino del ser absoluto. La realidad se me hace presente como noticia en la voz de la conciencia» ${ }^{10}$. No es, pues, un informe meramente teórico, sino una voz que clama, como corresponde a las noticias -intelectivassuministradas por la audición; habría que añadir que el clamor de la conciencia sólo se percibe en el silencio de otras solicitaciones.

Análogamente, desde la Fenomenología realista se ha mantenido que la voz de la conciencia no designa una potencia externa que desde fuera emita un dictamen, sino que resuena en la vivencia reflexivo-práctica, en que el sujeto se sabe (y se siente) interpelado, con anterioridad a todo juicio expreso de conciencia, en que el sujeto entra ya en cuentas consigo mismo ${ }^{11}$. Zubiri coincide con este enfoque fenomenológico en anclar la voz de la conciencia en la realidad del hombre, aunque no lo exponga de modo vivencial.

$10 \quad$ HD, 137.

11 «El juicio es algo secundario, que incluso puede debilitar la conciencia inmediata de culpa, en la medida en que este 'entrar en cuentas consigo mismo' como autosanción soberana puede funcionar como sustituto del auténtico arrepentimiento», H.-E. HengstenBerg: Grundlegung der Ethik. Königshausen \& Neumann, Würzburg 1989, 152. 
Cabe establecer un paralelismo entre la justificación y la voz de la conciencia, como enclaves antropológico-éticos. Así como la primera no me sitúa primariamente ante un tribunal externo, sino que designa una estructura antropológico-moral, aun cuando reclame igualmente una instancia objetiva que establezca su validez, también la voz de la conciencia está estrechamente conexa con la inquietud constitutiva del hombre, y es inexplicable sin ella, por más que requiera unos criterios de validación. Prescindir en una y otra de estas bases antropológicas equivaldría a un extrinsecismo y voluntarismo éticos, en todo caso ajenos al planteamiento del filósofo español.

En la justificación se encuentra la posibilidad no meramente como algo que no es efectivo, sino como lo posibilitante de la actuación moral, vale decir, como el poder efectivo que opera en la apropiación de las posibilidades. Pero, ¿de dónde procede este poder?, ¿cómo se transmite a las posibilidades meramente proyectadas? He aquí el punto de enlace entre la justificación y la felicidad, por cuanto la felicidad no es pura y simplemente una idea, sino lo que ejerce como poder en orden a la operatividad de las posibilidades que me apropio y que ya se me hacían presentes en la justificación. Ahora bien, tanto el bien moral como el deber están entroncados antropológicamente en la felicidad (según el modo que se expondrá) y la felicidad es inseparable de la comprensión que tiene el hombre de sí mismo como ser antepuesto a sus posibilidades proyectadas antes de hacer efectivo su comportamiento. Es lo que habremos de tratar a continuación sobre el trasfondo de la justificación como estructura antropológica que hace aparecer las posibilidades.

\section{El acceso antropológico al bien moral y al deber desde la idea de felicidad}

En los proyectos objetivos determinados es el hombre el que está proyectado sobre sí. Y en las realizaciones con que resuelve la situación en que está, el hombre se realiza o per-fecciona. Ambas versiones hacia sí mismo son posibles — según Zubiri- porque el hombre se tiene a sí mismo indeterminadamente y en orden a un máximo; lo cual le proporciona la idea de felicidad. El hombre es felicitario antes de buscar la felicidad porque está antepuesto a sí en su figura plenaria de hombre. Parafraseando a San Agustín, diríamos que sabe lo que son la felicidad y la perfección antes de encontrarlas, como posibilidades máximas de sí mismo, ya que en otro caso no podría buscarlas. Por ello, la felicidad se plantea en cada acto, previamente a su realización determinada, en vez de 
ser como una suma o compendio imaginativo de los actos ya realizados y realizables, como supuso Kant bajo la influencia empirista.

Así pues, la felicidad ya está apropiada por el hombre como posibilidad, y es lo que depone en cada acto de deponer su realidad en una u otra cosa. La felicidad es la fuente del bien apropiado. Que el hombre busque la felicidad necesariamente no es una constatación, sino la raíz (el estar sobre sî) de que esté abierto al bien, la posibilidad (efectiva) de todas las posibilidades apropiadas (problemáticas) ${ }^{12}$. Lo máximo en orden al bien (lo óptimo) es anterior a cualquier bien determinado. Semánticamente se comprueba que lo óptimo tiene que ver con opción, no es simplemente un posible bien de mayor magnitud que los otros.

En otras palabras: hay bienes morales porque el hombre es moral (tiene que apropiarse las posibilidades). Y el hombre es moral porque tiene ya apropiada la felicidad; o también: tiene que apropiarse las posibilidades porque está ya apropiado como máximo. El máximo de sí mismo se contrae a un bien o figura determinada: la felicidad es disyuntiva en principio en el estar-sobre-sí y luego se vuelve conjuntiva, con la apropiación progresiva o madurada de los distintos bienes elegidos. "Sólo hay felicidad (se entiende lograda, y no simplemente apropiada como posibilidad) si lo definitorio de cada acto es capaz de ser elevado a definitivo» ${ }^{13}$, y no meramente formar parte de una secuencia, como ocurre a lo largo de la sucesión de la vida terrena.

En tanto que apropiada, la felicidad ejerce un poder sobre el hombre. En efecto, las posibilidades proyectadas son todavía abstractas, teniendo que apoyarse como posibilidades en el poder de la felicidad, en la medida en que como posibilidad de las posibilidades ya ha sido apropiada ${ }^{14}$. «El hombre, por no poder existir más que bajo el poder absoluto de la felicidad, tiene inexorablemente la posibilidad de ser feliz o infeliz en cada una de las situaciones» ${ }^{15}$. La felicidad es entendida, en consecuencia, no meramente como la satisfacción o el cumplimiento de una tendencia, sino más radicalmente como un poder.

De este modo puede sortear Zubiri el pragmatismo de las posibilidades apropiables, según el cual cabría interpretar apresuradamente el anterior planteamiento. Se basaría en que las posibilidades en orden al bien componen un plexo pragmático. Así, la escalera de mano está para bajar las tuercas, las tuercas para remachar los clavos que aplico a la

SH, 407.

$\mathrm{SH}, 393$.

Como tantas otras veces, Zubiri hace un uso propio de la conceptuación heideggeriana de la posibilidad de las posibilidades, ya que en vez de aplicarla a la muerte la refiere a la felicidad como poder fundante de las posibilidades proyectadas.

$15 \mathrm{SH}, 402$. 
mesa, de la mesa me sirvo para apoyar los papeles... Pero lo decisivo es que estas posibilidades no se proyectan meramente en función de los resultados o efectos que cabe esperar de ellas, sino que como posibilidades dependen de la felicidad ya apropiada como poder, que les confiere su ser-posibles, en vez de tratarse de simples medios instrumentales.

Pero, en segundo término, también en la felicidad como posibilidad encuentra Zubiri la radicación antropológica del deber. En efecto, al estar sobre sí el hombre no puede por menos de estar entregado o debido a su propia felicidad, ya apropiada. Y como resultado tiene debitoriamente las posibilidades no como apropiadas, sino como apropiandas, en tanto que inscritas en la posibilidad indeterminada y apropiada desde el inicio que es la idea de felicidad. «Los deberes en plural, con su carácter impositivo, son deberes fundados en una cosa primaria y radical, que es el carácter debitorio del hombre en orden a su propia felicidad ${ }^{16}$.

No comparto, por consiguiente, en este punto la apreciación de A. Pintor-Ramos de que «si no existiesen conflictos dentro de lo que Zubiri llama la estimación de bienes y valores, no existiría la necesidad ni siquiera la posibilidad de una normatividad moral» ${ }^{17}$. Esta posible objeción, que sería aplicable a la Axiología scheleriana, como he mostrado en otro lugar ${ }^{18}$, no lo es tanto si se la dirige a una ética que ancla el deber en la realidad debitoria del hombre, por tanto con anterioridad a cualquier colisión entre las estimaciones y preferencias a favor de unos u otros bienes.

Por otro lado, en tanto que poder indeterminado, la felicidad requiere un poder correlativo que la saque de la indeterminación y se ejerza sobre ella en el modo adecuado, tal que como felicidad pueda reconocerse en él. No otra es para Zubiri la base fenomenológica del deber. «La posibilidad en tanto que es más o menos potente para hacer feliz, en tanto que es más o menos apropianda en orden a la felicidad, es lo que llamamos un deber. El deber no es una posibilidad entre otras, sino aquella que es más conducente a la felicidad del hombre» ${ }^{19}$.

Con esto Zubiri enraíza antropológicamente el deber, frente a su consideración por Kant como un factum a priori de la razón pura práctica. El deber es para... el hombre, y su doble supuesto antropológico reside en que haya posibilidades no apropiadas de hecho, así como en la

\footnotetext{
$16 \mathrm{SH}, 412$.

17 A. Pintor-Ramos: Realidad y sentido. Desde una inspiración zubiriana. Universidad Pontificia de Salamanca, 1993, 116; en el mismo sentido, p. 70.

18 U. FERRER: Desarrollos de ética fenomenológica. Moralea, Albacete 2003, 39-40.

19 SH, 408-9.
} 
posibilidad suprema ya apropiada de la felicidad, dada en su punto de partida. En efecto, el deber es simultáneamente lo no realizado todavía pero realizable tanto como lo ineliminable con la misma ineliminabilidad que caracteriza al horizonte de la felicidad.

El poder de lo real se actualiza como deber. Pero aún hay que distinguir - distinción que juega un papel de primer orden en toda la obra de Zubiri- entre lo real ejerciendo su poder en forma de deber, a partir de la estructura antropológica básica, y los contenidos apropiables o talidades, que dan una u otra especificación al deber y a los que designamos igualmente como deberes. Esta distinción se vuelve más nítida si diferenciamos entre mi deber (propio del hombre) y lo debido o los deberes que otorgan su talidad al primero. Ya se advierte que no se trata de una separación (pues en ningún modo el deber es una idea a priori, como en Kant), sino de la distinción entre lo trascendental y lo talitativo aplicada al deber.

La ordenación natural a la felicidad es, así, el dinamismo con el que engarza la invocación con que se presenta el deber ante el hombre, especificando la exigencia de felicidad actuante como un poder desde el inicio. E igual que la felicidad deja indeterminado el campo de los bienes apropiables, también el deber, una vez que se ha vivenciado en concreto, deja en indeterminación el radio de los bienes que se han de ir presentando como apropianda y que darán lugar a nuevos deberes. Por ello, los deberes especificados son múltiples, mientras que la idea de felicidad subyacente es unitaria ${ }^{20}$. De este modo, evita Zubiri toda sombra de sospecha de que el deber aparezca como un sometimiento injustificado, vale decir, renuente a la justificación como estructura antropológico-moral.

Si a la felicidad el hombre está ligado y no puede no estarlo, respecto de las posibilidades que la felicidad le abre se encuentra ob-ligado en razón del poder que dimana de ellas. Así enlaza el deber con la obligación a través del poder, que primariamente pertenece a la felicidad como exigencia: «Precisamente en la medida en que está ya ligado a esa posibilidad de la felicidad, está respecto de las demás no ligado, sino 'ob-ligado'; he ahí la estructura formal de la obligación. La obligación es la forma en que el deber se apodera del hombre» ${ }^{21}$.

Pero, ¿por qué nos vivimos obligados, siendo que la obligación se refiere a un término externo al hombre como posibilidad suya? ¿En qué se funda el «ob» de la obligación? En su última obra El hombre y Dios la respuesta de Zubiri apunta a fundar el término objetivo de la obligación

$\begin{array}{ll}20 & \text { SH, } 411 . \\ 21 & \text { SH, } 410 .\end{array}$

VERITAS, $\mathrm{N}^{\circ} 23$ (Septiembre 2010) 
en la realidad mediante la religación constitutiva del hombre. El «ir a» característico de la obligación se funda en un previo «venir de», por el que estamos ya re-ligados al poder de lo real, y en útimo término a Dios. El apoderamiento en que consiste la religación no se ejerce sobre la realidad personal ya constituida, como es el caso en la obligación, sino que «es una respectividad constitutiva» ${ }^{22}$ y posibilitante del estar obligados. También se muestra la precedencia de la religación a la obligación en que el estar vuelto el hombre a la conciencia moral para oírla y, en este sentido, el atenerse a ella - previo al atenerse a sus dictados- son manifestaciones de la religación posibilitantes del fenómeno de la obligación: «la conexión del hombre con su conciencia no es una obligación moral; es una religación» ${ }^{23}$. Mas podemos seguir preguntando: ¿cómo acontece la conversión de la religación en obligación?

Hemos de partir de que el poder de lo real se hace efectivo en sus vectores intrínsecos que son las cosas reales $y$, por tanto, sin que la figura concreta en que el hombre se realiza venga forzada por la realidad, aun cuando haya de desenvolverse por necesidad dentro de ella. La opción tiene aquí su lugar, no referida sólo a una determinada acción, sino como ad-opción de una forma de realidad en la acción elegida. «En la religación, pues, el hombre está enfrentado con el poder de lo real, pero de un modo optativo» ${ }^{24}$. Pero justamente este momento opcional, contenido en la forzosidad de la religación, es lo que deja a salvo el modo libre como el hombre es reclamado por la obligación (por más que esta libertad no afecte a los contenidos obligatorios en tanto que apropianda).

La estructura de la ob-ligación tiene su preludio en la intelección correspondiente al sentido kinestésico, donde la realidad se me presenta en hacia, abriendo trascendentalmente la vía de la razón al ámbito direccional de la obligación. «En la kinestesia ya no tengo presente la realidad, ni su noticia, etc. Sólo tengo la realidad como algo en 'hacia'. No es un 'hacia' la realidad, sino la realidad misma como un 'hacia'. Es un modo de presentación direccional» ${ }^{25}$. La intelección acorde con la kinestesia es tensión dinámica: «es un modo de aprehensión intelectiva en hacia» ${ }^{26}$. De modo congruente con ello, en la ob-ligación estoy dirigido dinámicamente al término real al que previamente estoy re-ligado por el poder de lo real, en el que estoy implantado.

$\begin{array}{ll}22 & \text { HD, 92. } \\ 23 & \text { PFHR, 54. } \\ 24 & \text { HD, 374. } \\ 25 & \text { IRE, 101-2. } \\ 26 & \text { IRE, 105. }\end{array}$


Pero la determinación de los deberes excede de la intelección primordial, remitiendo al ejercicio de la razón. «La inteligencia tiene que considerar lo que es eso de la felicidad en ese ejercicio ulterior de la inteligencia que es la razón. Los deberes en plural no transparecen más que por un acto de razón» ${ }^{27}$. A la inteligencia sigue el logos, del que dependen la opción y la decisión o juicio moral, que son las fases subsiguientes a la aprehensión primordial del deber como obligación. En cuanto a la marcha subsiguiente de la razón, esboza en un primer momento lo que «debería ser» de modo universal y en un segundo momento pasa del «debería ser» al «deber ser» en concreto. Bien entendido que la realidad del deber se presenta ya en la intelección primera. «El logos y la razón no hacen sino colmar la insuficiencia de la aprehensión primordial, pero gracias a ello, y sólo gracias a ello, se mueven en la realidad. La maduración modal no es constitutivo formal del inteligir, pero es un inexorable crecimiento determinado por la estructura formal del primer modo, de la aprehensión primordial de la inteligencia sentiente» ${ }^{28}$. El esbozo del «debería», como sistema de referencia sugerido por la razón, se verifica o cumple posteriormente en la determinación fundamentada del deber.

Más, ¿cómo tiene lugar este proceso? Según Zubiri, los tres momentos en que se despliega la moralidad del deber son moralidad transmitida, conciencia moral, como intelección propia de lo que ha de ser apropiado, y uso de razón, como capacidad de medir o verificar por sí mismo la adecuación entre lo apropiandum y el ideal moral de hombre. El tercero de ellos incumbe a la razón inquiriente y es lo que más brevemente designamos usualmente como obrar responsable. «Moralidad, conciencia y responsabilidad no son términos convergentes. Toda responsabilidad supone conciencia y toda conciencia supone moralidad. Lo recíproco, sin embargo, no es cierto. Ni todo lo moral es esencialmente consciente ni toda conciencia moral es responsable» ${ }^{29}$. El momento de la moralidad transmitida tiene por función vehicular social e históricamente el hecho moral, antes que la conciencia moral ejerza su operatividad. Zubiri llama dimensiones a estas coordenadas social e histórica en que está inscrita la moralidad. Trataremos seguidamente lo específico de cada una.

\footnotetext{
27 SH, 412.

28 IRA, 324.

$29 \mathrm{SH}, 436$.
} 


\section{Las dimensiones social e histórica de la moralidad}

La socialidad es la vinculación constitutiva con los congéneres partiendo de la individualidad diferencial de cada cual, como miembro de la misma especie, y esto desde el grado más incipiente de la personalidad. Esta «individualidad diferenciada no es una dimensión de la personeidad, sino de la personalidad. Soy específicamente individual según mi personalidad. Y no olvidemos que el ser del hombre es unitariamente natural y apropiado ${ }^{30}$. En el planteamiento aristotélico el recurso prematuro al concepto de sustancia (algo separado, jorismós) en aplicación a los individuos humanos, es lo que habría impedido advertir en ellos la habitud social relacional constitutiva ${ }^{31}$. Zubiri opone a ello que si bien la aprehensión de realidad es irreductible en los distintos individuos o individual, se efectúa por la mediación de los otros individuos y de sus pertenencias básicas; derivadamente, la realización personal individual habrá de incluir la referencia a los demás bajo una serie de modos. Más abajo indagaremos cuáles son estos diversos modos, pero antes extraigamos algunos corolarios.

En primer lugar, individualidad y socialidad no son dos aspectos realmente distintos, menos aún contrapuestos, más bien son dos dimensiones, en el sentido preciso que tiene el término en Zubiri: como distintas refluencias de un mismo esquema filetico sobre la personalidad; en efecto, para la conformación individual se requieren los otros, se es di-verso, y recíprocamente la habitud hacia el otro es intrínseca al individuo, que está en versión hacia el otro. En este sentido, la soledad no sería de por sí un signo de autenticidad, ya que acusa de modo negativo la exigencia de alteridad inherente al hombre. Hay en ello una crítica larvada al análisis orteguiano de la intimidad y autenticidad como soledades radicales ${ }^{32}$, por cuanto es un análisis que no cuenta suficientemente con la apertura a la realidad, indisociable del me y del mí - ambos reveladores de la intimidad-, como formas pronominales de una acción verbal públicamente expuesta.

La individualidad no significa, pues, en el hombre meramente que sea un ejemplar entre otros de una especie, sino alguien diferenciado

30 SH, 192-3. La diferencia entre personeidad o ser persona y personalidad o hacerse persona mediante los propios actos es precisa para poder anclar los actos personales en una realidad sustantiva identificable.

31 TDSH, 48.

32 «La vida humana sensu stricto por ser intransferible resulta que es esencialmente soledad, radical soledad», J. ORTEGA Y GASSET: El hombre y la gente, Obras, VII, Alianza, Madrid 1983, 105. En otro lugar: «Mi humana vida... es, por esencia, soledad», ibíd., 115. 
cualitativa y realmente de los demás miembros de la especie, desde luego fileticamente, pero a una con ello en su ser persona. Somos diversos en una serie inmensa de notas, pero somos sobre todo diversos trascendentalmente en el respectivo yo, esto es, en la actualización absoluto-relativa de nuestra realidad diferencial (lo que técnicamente llama Zubiri dimensionalidad del yo). «Si la diversidad de mis notas es una diferencia talitativa, la diversidad respectiva de las formas de realidad es una diferencia trascendental. Es una diversidad del yo, del tú y del él: el hombre está determinado por sus notas a ser absoluto, y está codeterminado por las demás personas a serlo de modo diverso» ${ }^{33}$.

Otra consecuencia de lo anterior es que los derechos sociales (los así llamados derechos de segunda generación) no son una concesión otorgada al individuo por una instancia externa, sino que están afincados en la constitución natural y personal del ser humano. Por ser personalmente realidad moral, la alteridad se manifiesta moralmente en unos lazos sociales que dan lugar a derechos inherentes al hombre como miembro de la colectividad.

Pero, ¿cuáles son los modos primordiales en los que se manifiesta la condición social del individuo? En una somera enumeración Zubiri hace mención de la socorrencia o necesidad de ayuda, la educación, la convivencia y la compañía. La vinculación al otro se hace patente inicialmente como socorrencia en la búsqueda de alimento y de amparo. «Por sentir precisamente la necesidad de socorro, el hombre está constitutivamente abierto al otro» ${ }^{34}$. Los demás «se encuentran en mi vida como aquello que representan al acudir a un socorro; la unidad entre el acudir y la ayuda es lo que expresa el concepto de socorrencia» ${ }^{35}$. En cuanto a la educación, Zubiri la entiende primariamente como la transmisión a cargo de los educadores del sentido humano de las realidades que son aprehendidas como ajenas. Para ello hay que contar con que la aprehensión de realidad concerniente a lo otro viene acompañada por el sentido que le es transmitido al educando y que este descubre.

Este entreveramiento de individualidad y alteridad seguirá hasta los estadios más avanzados de la vida moral. Reparemos, a título de ejemplo, en las actitudes moralmente opuestas del egoísmo y la benevolencia. El egoísmo sólo es posible desde la versión primera a los otros; es una toma de posición en relación con el previo estar referido a los demás en el modo de ser un «cada cual» o, lo que es lo mismo, un yo que es el «alter

\footnotetext{
33 TDSH, 25.

$34 \mathrm{SH}, 236$.

35 Ibíd.
} 
mío» entre los demás «alteri». Inversamente, la benevolencia, como actitud moralmente positiva que hace entrar al otro en el radio de mi querer, se dirige al «otro que yo»y, por tanto, implica la afirmación absoluta por la que se confronta el yo con todo lo que no es él. «Radicalmente por mucho que uno viva para sí mismo está viviendo para otros, y recíprocamente el desvivirse por los otros es una forma de vivir para sí. El alter como alter está ya en mi habitud y no consiste en mera multiplicidad numérica; el ego como ego está modalizado en su forma de ser cada cualı ${ }^{36}$.

La socialidad de la educación se pone de relieve en la mentalidad, entendiendo por tal el modo de pensar y de conducirse en la vida que tiene cada cual en tanto que afectado por los demás. La mentalidad no intelige, sino que es el modo comunal de la inteligencia, que es el único sujeto próximo de la intelección. Por tanto, tampoco la realidad inteligida puede ser el término o asunto de la educación, en la misma medida en que la realidad no se confunde con la mentalidad, sino que esta es aquello a través de lo cual la mente accede a la realidad.

Por lo que hace a la convivencia o modo social subsiguiente, no es todavía la interacción, en la que cifraba Max Weber lo constitutivo de la acción social, sino algo previo: la habitud estructural previa de alteridad respecto de cualquier hombre. Es el momento constituyente del nosotros colectivo, pero en función trascendental, que hace que la realidad aparezca en común: un mismo mundo externo, una misma cultura ambiental... Mas como a su vez los otros como personas se autoposeen en tanto que realidades, interviene un segundo dinamismo trascendental de convivencia, que es el espacio de la comunión interpersonal. En ambos órdenes tiene lugar la apropiación de posibilidades en que se reconoce la esfera ética. «La apropiación (por convivencia) consiste formalmente en que hago de la vida de los demás una posibilidad de mi propia vida... Las vidas de los demás, o los demás en tanto que vivos, en cuanto constituyen posibilidades de mi propia vida, es la única forma en que puedo apropiarme la vida de los demás» ${ }^{37}$.

Esta duplicidad dentro de la convivencia -la colectividad indiferenciada y la comunidad de personas- da lugar a que idénticos vocablos, como solidaridad, publicidad, comunicación..., adquieran una significación ética distinta, según que los refiramos a la colectividad anónima o a los ámbitos de participación en lo común interpersonal, de acuerdo con la clasificación anterior. La ética se diversifica, así, en empresarial, político-institucional, familiar, educacional..., aun contando

$\begin{array}{ll}36 & \mathrm{SH}, 322 . \\ 37 & \mathrm{SH}, 306 .\end{array}$


en todos los casos con el momento común de publicidad. Sin embargo, esta distinción es, por así decir, tipológica (en el sentido de Weber y Schutz), ya que en toda agrupación humana se dan en mayor o menor grado la colectividad y la comunión; conforme a la primera los individuos se organizan e institucionalizan sus modos de aparecer en público, conforme a la segunda tiene lugar la compenetración en la distancia. Es obvio, por ejemplo, que la solidaridad debida a la división del trabajo — estudiada por Durkheim - no tiene el mismo alcance ético que la solidaridad entre los miembros de una familia o que el espacio de lo público se diversifica en sus exigencias en cada uno de estos y de los otros marcos.

Por último, en la compañía se hace presente el particular poder de lo social que como irradiación reside en los otros. En la compañía se hace especialmente operativo el ejemplo, que juega un papel tan relevante en las éticas fundadas en los modelos personales, como en Scheler, o en la moral de la aspiración de Bergson. Zubiri amplía el concepto de causalidad hasta extenderlo a la esfera interpersonal, como fuerza irradiadora del ejemplo. «La ejemplaridad no consiste en que hay un modelo, un paradigma; la ejemplaridad tiene un poder positivo de irradiación, en lo que reside el carácter poderoso de la ejemplaridad $\rangle^{38}$.

$\mathrm{Si}$ advertimos, por otro lado, que las posibilidades socialmente apropiables no son abstractas, sino que están ahí o han tomado cuerpo y que tampoco se presentan desligadas entre sí, sino que se articulan en sistema, habremos de concluir que su dinamismo no es externo a ellas, por el contrario, ha de decirse que las penetra constitutivamente. Tal dinamismo, cuyo resultado es el alumbramiento de nuevas posibilidades o innovación, es lo que entiende Zubiri por dimensión histórica del hombre. La historia es sistema dinámico de posibilidades ${ }^{39}$.

¿Bajo qué aspecto este dinamismo histórico despersonalizado forma parte de la condición moral del hombre? No ciertamente por su sujeto próximo, que es el cuerpo social; tampoco por sus efectos, ya que no coinciden necesariamente con las intenciones y propósitos de sus agentes. Pero sí como espíritu objetivo, según la denominación hegeliana, aunque cambiándole el sentido que tiene en Hegel de ser algo subsistente. Si lo moral se funda antropológicamente en la apropiación de posibilidades y estas deben su curso histórico a su disposición sistemática concreta, entonces toda moral se encuentra ab initio siendo histórica, encuadrada en un espíritu objetivo. La historicidad en la moral equivale a la mundificación de los sucesos personales, vale decir, a su

\footnotetext{
$38 \mathrm{SH}, 322$.

39 EDR, 268.
} 
instalación en un mundo con unos rasgos espirituales objetivos, como se advierte en la datación de tales sucesos como hechos, con sus condicionantes y efectos externos, con su incardinación en una u otra generación.

En otros términos: desde el punto de vista de su transcurso contemplado en perspectiva - tal como hace el historiador- la historia es la desrealización de las posibilidades antes proyectadas y hechas efectivas; historiarlas no es sino verlas como ya transcurridas. Pero previamente y en su núcleo fundante se halla la historia como capacitación ${ }^{40}$ social de un sistema de posibilidades: y es aquí donde se encuadran las posibilidades humanas reales - que están en la raíz del comportamiento moral-, al encontrar su inserción mundanal en respectividad con las otras posibilidades ya realizadas.

¿Cómo se lleva a cabo el dinamismo histórico? Pronto se advierte que no puede ser por transmisión, ya que ello comporta fijeza en lo que se transmite. «Las formas de vida en 'la' realidad no sólo no son de hecho término de transmisión genética, sino que por su propia índole no pueden serlo precisamente porque son en amplia, pero inexorable medida término de opción. Por esto es por lo que la historia no es mera transmisión» $»^{41}$. La forma de legar algo de modo que el receptor tenga que aceptarlo en su realidad es lo que llamamos tradición (apódosis) o entrega (de tradere, entregar). Para Zubiri la historia se hace por entrega de forma de vida en la realidad, en la que está implicada una opcionalidad por un sentido real. Montada sobre la transmisión genética, la tradición le añade no simplemente un «pasarse el testigo» de unos a otros individuos y comunidades, sino estrictamente una entrega de la realidad, que permanece abierta por su sentido a nuevas conformaciones. «Lo tradicional es la realidad entregada y no lo que de ella atestigua el testimonio» ${ }^{42}$.

Atendiendo sólo a su sentido, la historia es un relato reconstruido y verificable en unos documentos y testimonios. Pero no es esto lo que

40 El término «capacitación» fue técnicamente acuñado por Zubiri para referirse al rendimiento histórico en las Lecciones de 1974 sobre la dimensión histórica del ser humano (TDSH). La capacitación se diferencia de la actualización de una facultad en que recae sobre la facultad misma potenciándola en cuanto principio (TDSH, 97). Trasladada a la historia, la capacitación designa a esta como posibilitadora de nuevas realizaciones sin modificar las potencias ni las facultades humanas; lo cual es consecuencia de que no haya un sujeto idéntico o mismidad subyacente a los cambios históricos. Es un término el de capacitación que sustituye al histórico «hacer un poder», empleado hasta entonces desde NHD (1942).

$41 \mathrm{SH}, 201$.

$42 \mathrm{SH}, 205$. 
Zubiri quiere decir con la entrega de realidad. El sentido podría integrarse en un fictum narrativo y permanecer incólume en relación con el sentido histórico. Lo que se lega históricamente a cada hombre consiste más bien en un sistema de posibilidades, a las que el destinatario habrá de dar una u otra conformación vital. Nos vuelven a aparecer las posibilidades, a partir de cuya apropiación es como se hace efectiva la realidad moral. Pues las posibilidades que el hombre se apropia no están suspendidas en el vacío, sino que se adhieren a aquellas que me vienen de los demás por tradición. De este modo, la historia no proporciona sólo la mundificación a los sucesos de mi vida, sino también una continuidad intrínseca con mis antecesores a través de las posibilidades sobre cuyo trasfondo he de configurar la realidad de mi vida.

Desde estos supuestos se entiende, por ejemplo, que la nota ética de la responsabilidad no concierna sólo a mis propias acciones en cuanto terminan en mí, sino que tenga un origen y unos destinatarios que son otros. Por aquí se enlazaría en alguna medida con las consideraciones de E. Lévinas sobre la responsabilidad. En virtud de la dimensionalidad social la responsabilidad me viene de alguien otro, que me la puede reclamar. Yo soy responsable porque puedo responder, pero inseparablemente porque hay otro que se me muestra como otro o innominado al hacerme responsable (responsable tiene que ver con pondus, el peso o la carga que echan desde fuera sobre mí, de ningún modo un mero objeto intencional). $\mathrm{Y}$ en virtud de la dimensionalidad histórica estos otros indeterminados se extienden también a quienes me han precedido o a quienes vendrán después, haciendo posible una responsabilidad ética ante la historia en general.

\section{Complementos fenomenológicos y antropológicos}

En su época madura Zubiri se aparta decididamente del punto de partida de las estructuras de la conciencia adoptado por la Fenomenología $^{43}$. Probablemente sea este el motivo por el que en su análisis del hecho moral no aparece el sentido (sustituido inicialmente por las cosas-sentido y posteriormente acomodado hasta hacerle converger con las posibilidades en que se despliega la vida moral, como

43 Si bien esta crítica se dirige in recto a Husserl, Zubiri la extiende a todos aquellos filósofos del siglo XX que en una u otra medida mantienen en sus análisis un reducto de conceptos procedentes de la subjetividad, como ocurre con la capacidad de ensimismamiento del sujeto en Ortega o con el mundo de la vida intencional en Habermas. Es un aspecto estudiado expresamente por J. COROMINAS: Ética primera. Aportación de Xavier Zubiri al debate ético contemporáneo, cap. VII: "El punto de partida". 
ha expuesto A. Pintor-Ramos) ni tampoco tiene cabida la intencionalidad de los actos humanos. Sin embargo, considero que son conceptos que apenas se pueden excluir del punto de partida de la moralidad y que en particular la descripción fenomenológica los ha esclarecido en su mutua implicación.

La ética husserliana ha ampliado la noción clásica de intencionalidad de la voluntad, al adjuntarle el sentido ${ }^{44}$, primeramente encontrado por la Fenomenología en el ámbito lingüístico del acto de dar significado. El sentido es lo que recoge en su unidad objetiva específica una pluralidad de actos psíquicamente diferenciados. En los actos de voluntad, el sentido introduce una cualificación idéntica en actos numéricamente separados, cualquiera que sea el momento en que se realicen y cualquiera que sea su agente. De modo paralelo, el fin intencionado da unidad última a actos especificados de modo próximo por diferentes sentidos. Así, desde la unidad de una finalidad operante, pero no inmediata, puedo disponer de una cierta perspectiva en la vida moral, que me lleve a completar - y eventualmente rectificar- la orientación de actos que ya han sido proyectados.

Esta vía relativa a los actos de voluntad no ha sido surcada por Zubiri - aunque tampoco es incompatible con su análisis del hecho moral-, ya que centró el examen de las voliciones en el momento preciso de la fruición en la realidad. Pero aun concediéndole que la volición del bien como real tiene prioridad fundamental sobre la intención finalista y que el poner en ella la esencia del acto voluntario es una de sus aportaciones antropológico-éticas decisivas, se hace preciso reconocer que existen asimismo conexiones teleológicas en las acciones humanas, de modo que un fin no pro-puesto, sino implícito sea no obstante lo que dirige y permite interpretar la pro-posición intencional actual.

Incluso no es infrecuente que el sentido de un acto sólo se revele en su integridad a la luz de actos ulteriores, o bien que estos últimos modifiquen el sentido que inicialmente se asignó al acto. Zubiri menciona el hecho moral del arrepentimiento en este contexto, pero no está integrado en una consideración moral general sobre el sentido en los actos humanos. En este orden, la reflexión fenomenológica se completa con una aproximación hermenéutica, que desvele comprensivamente las claves de aquellos actos que están integrados en un mismo contexto narrativo.

44 E. HusserL: Renovación del hombre y de la cultura. Ensayo 3, Anthropos, Barcelona 2002. 
Pero no sólo por el lado de los actos, sino también por la vertiente de lo querido la finalidad resulta inexcusable. No se quiere, en efecto, del mismo modo aquello que se presenta como fin de suyo que lo que es ordenable como medio a la realización de un fin-efecto. No se trata con el primero del fin propuesto como objetivo o meta (Ziel), sino del fin en sí mismo (Zweck an sich), como revela la tercera formulación del imperativo categórico kantiano, en que se discierne éticamente entre la persona como merecedora de respeto y los medios instrumentales.

El intento de D. Gracia ${ }^{45}$ ha ido precisamente en el sentido de traducir a términos formalistas próximos a los kantianos lo que entiende es el imperativo ético fundamental zubiriano: «Obra (es decir, aprópiate las posibilidades) de tal modo que no utilices nunca tu realidad personal, la realidad de las demás personas y de la Humanidad en su conjunto como medios, sino como fines en sí mismos». Abunda en la misma idea cuando dice que «la obligación es formal, no forma parte de ningún contenido concreto ${ }^{46}$. Pero dejando aparte la cuestión controvertida del formalismo del bien en Zubiri (que no veo conciliable con la afirmación de la realidad del bien sólo en los bienes concretos), lo que con aquella fórmula se hace pasar por zubiriano es la incorporación al bien moral de categorías de la razón práctica, como fin en sí y medios. Sin embargo, es una tarea no acometida de intento por Zubiri (su mención del hombre como fin en algún lugar es sólo ocasional ${ }^{47}$ ), además de no encontrarse bases para ello en su análisis fruitivo de la volición del bien.

Otra noción débilmente entrevista por Zubiri son los hábitos prácticos y cognoscitivos, a los que en términos generales reemplaza por las habitudes, como modos primarios de habérselas el viviente con las cosas de su entorno ${ }^{48}$. Pero entre los principios antropológicos que hacen efectiva la moral entiendo que no cabe pasar por alto el hábito de la voluntad, no como mero factor psicológico de aprendizaje, sino en tanto que afecta intrínsecamente a la principiación de los actos: el hábito no deja intacta la facultad como principio de actos, sino que la faculta para operaciones de las que en su ejercicio primero y natural era incapaz. Esta ausencia es tanto más llamativa cuanto que Zubiri invoca repetidas

\footnotetext{
45 D. Gracia: Fundamentos de Bioética. Eudema, Madrid 1989, 489.

46 D. Gracia: "Zubiri en los retos actuales de la Antropología", en A. Pintor Ramos (coord.), Zubiri desde el siglo XXI. Publicaciones Universidad Pontificia de Salamanca, 2009, 156

$47 \mathrm{SH}, 432$.

48 Para evitar equívocos, los hábitos prácticos forman parte, dentro de la clasificación aristotélica, de la categoría o predicamento intrínseco de la cualidad, mientras que la habitud es una categoría o predicamento independiente.
} 
veces la noción de potencia operativa y la facultación exigida en ella para la realización de sus actos.

Se trata de un concepto central en la Ética aristotélica, pero cuyo desarrollo apenas es compatible con la primacía que Aristóteles otorga en otros lugares a la sustancia (ousía) y al acto en el sentido de entelejeia (el otro sentido es enérgeia). Pienso que se podría prolongar la crítica de Zubiri a la sustancia como hypokeímenon, en su aplicación al hombre, con el tratamiento de la infinitud operativa de la inteligencia y la voluntad, que hace insostenible su adscripción como accidentes a una sustancia definida por una forma sustancial realizada materialmente.

$\mathrm{Si}$ esta sustancia comunica su perfección existencial a los accidentes y, sin embargo, el acto de estos excede las potencialidades de la sustancia, es que el modelo «sustancia-accidentes» no resulta el más apropiado para explicar la relación entre el hombre y sus facultades superiores. Y si la sustantividad abierta zubiriana toma el reemplazo a la sustancia en el hombre, ¿nos colocaría ello tal vez en mejor situación para dar cabida al crecimiento ilimitado de inteligencia y voluntad mediante los hábitos, dado que es una sustantividad en respectividad consigo misma? Por otro lado, lo que Zubiri llama naturalización de la libertad en la voluntad ¿no queda mejor expuesto en los términos de una elevación de la naturaleza al nivel de la libertad por medio de los hábitos?

Son preguntas no fáciles de responder, ya que habría que reacomodar el constructo de sistema para que tolere la existencia de notas en él que se desarrollen unilateralmente e incidan sobre las demás transformándolas, algo así como lo que sucede en el ser vivo, que en vez de gastar energía en su desarrollo, la produce y está en condiciones de asimilar las sustancias inorgánicas de-sustanciándolas. El intento de Pilar Fernández Beites de acoplar el modelo sistémico con la actividad inmaterial de las potencias superiores entiendo que va en esta dirección: «La tesis que yo defiendo es que el subsistema psíquico del hombre es, en realidad, una sustancia, es decir, es un subsistema simple (con simplicidad en sentido estricto). La relación entre las notas simples no es sistemática, de coherencia, sino de inherencia en un yo simple» ${ }^{49}$. Habría que añadir que la sustancia aquí mencionada difiere a su vez de la aristotélica en que no viene actualizada adicionalmente por accidentes determinativos.

Una dificultad interna al pensamiento de Zubiri para dar cabida al hábito está en su noción indistinta de máximo moral ya apropiado, condición de apropiación del bien moral. Pues, ¿cómo se puede crecer en

49 P. FERnÁndez BeITES: "Teoría de la sustantividad: Una necesaria ampliación de la teoría de la sustancia”, Pensamiento, vol. 64, n 240 (2008), 222. 
la apropiación moral, si se parte de la instalación en el máximo y de su declinación subsiguiente en las posibilidades apropiables? El único modo que encuentro de dejar sitio al hábito moral desde estos supuestos, es por ahondamiento en la diferencia que el propio Zubiri esboza entre el ideal (el hombre antepuesto a sí mismo) y la realización de la felicidad, en cuya integridad habrían de tener parte las virtudes o hábitos morales. «Esta articulación entre lo que hay de realidad y lo que hay de irrealidad... en el caso de la felicidad del hombre, cobra un nombre preciso. No es meramente idea, es ideal $»^{50}$. Sin embargo, no es claro que el hábito práctico o virtud se comporte como una realización del ideal de felicidad; más bien tiene el sentido de un afianzamiento en el bien siguiendo la dinámica intrínseca a la voluntad.

En relación con los hábitos cognoscitivos, tampoco parece que desempeñen papel alguno relevante en la Noología zubiriana. Su lugar lo ocupa la coactualidad del acto de inteligir y lo inteligido o noergia del estar implantado en la realidad, extensivo a lo inteligido y al sujeto que se hace cargo de ello al inteligirlo. Pero, ¿cómo llega el sujeto a conocerse diferenciadamente de lo conocido? Si no puede ser por objetivación y tampoco por reflexión en la línea objetiva (como una «reditio in se ipsum»), sólo queda que sea por iluminación de la operación desde un modo de conocimiento más alto que el operacional y que incluye las operaciones como realizadas. Tal es el modo de conocer por hábitos. La conciencia moral puede inscribírsela en este orden de conocimientos, como captación supraaprehensiva que acompaña a las distintas operaciones (la denominación es de Scheler: «übergreifende Erkenntnis»), y completaría el análisis que hace Zubiri de la voz de la conciencia.

Sumario: 1. La justificación y la voz de la conciencia como enclaves antropológico-morales; 2. El acceso antropológico al bien moral y al deber desde la idea de felicidad; 3. Las dimensiones social e histórica de la moralidad; 4. Complementos fenomenológicos y antropológicos.

$50 \mathrm{SH}, 393$. 